\title{
A BIOMEBGC-BASED EVALUATION OF DRYNESS STRESS OF CENTRAL EUROPEAN FORESTS
}

\author{
H. Buddenbaum ${ }^{\text {a, } *, \text { J. Hientgen }}{ }^{\text {a }}$, S. Dotzler ${ }^{\text {a }}$, W. Werner ${ }^{\text {b }}$, J. Hill ${ }^{\text {a }}$ \\ ${ }^{a}$ University of Trier, Environmental Remote Sensing and Geoinformatics, 54286 Trier, Germany - \\ (buddenbaum, s6johien, dotzler, hillj)@uni-trier.de \\ ${ }^{\mathrm{b}}$ University of Trier, Geobotany, 54286 Trier, Germany - werner@ uni-trier.de
}

KEY WORDS: Ecophysiological forest modelling, climate change

\begin{abstract}
:
Dryness stress is expected to become a more common problem in central European forests due to the predicted regional climate change. Forest management has to adapt to climate change in time and think ahead several decades in decisions on which tree species to plant at which locations. The summer of 2003 was the most severe dryness event in recent time, but more periods like this are expected. Since forests on different sites react quite differently to drought conditions, we used the process-based growth model BiomeBGC and climate time series from sites all over Germany to simulate the reaction of deciduous and coniferous tree stands in different characteristics of drought stress. Times with exceptionally high values of water vapour pressure deficit coincided with negative modelled values of net primary production (NPP). In addition, in these warmest periods the usually positive relationship between temperature and NPP was inversed, i.e., under stress conditions, more sunlight does not lead to more photosynthesis but to stomatal closure and reduced productivity. Thus we took negative NPP as an indicator for drought stress. In most regions, 2003 was the year with the most intense stress, but the results were quite variable regionally. We used the Modis MOD17 gross and net primary production product time series and MOD12 land cover classification to validate the spatial patterns observed in the model runs and found good agreement between modelled and observed behaviour. Thus, BiomeBGC simulations with realistic site parameterization and climate data in combination with species- and variety-specific ecophysiological constants can be used to assist in decisions on which trees to plant on a given site.
\end{abstract}

\section{INTRODUCTION}

Dryness stress is expected to become a more common problem in central European forests due to the predicted regional climate change. Forest management has to adapt to climate change in time and think ahead several decades in decisions on which tree species to plant at which locations. The late summer of 2003 was the most severe dryness event in recent time, but more periods like this are expected to occur in the future (Gobron et al., 2005). Forest management is facing the challenge of having to decide on the best tree species and variations to plant on each site for the climate of future decades.

A model of bio-geo-chemical cycles that simulates, among other variables, water states, plant photosynthesis, gross primary productivity (GPP), and net primary productivity (NPP) based on site and climate data is expected to show the effects of dryness periods on forest trees, so that decisions on which trees to cultivate on which sites can be aided. BiomeBGC is such a model. It is based on its predecessor Forest-BGC (Running and Coughlan, 1988; Running and Gower, 1991; Hunt et al., 1991) and is a general ecosystem process model designed to simulate daily biogeochemical and hydrologic processes from stand to global scales (Kimball et al., 1997; Thornton et al., 2002). The model is not designed for single-tree considerations or for managed forests, but can be adapted for these (Cienciala and Tatarinov, 2006; Tatarinov and Cienciala, 2006; Schlerf et al., 2005). Adaptations have also been made for successional change (Bond-Lamberty et al., 2005), for hydrological changes
(Pietsch et al., 2003), and for dynamic mortality (Pietsch and Hasenauer, 2006).

We ran BiomeBGC simulations of tree growth for deciduous broadleaved forests (DBF) and evergreen needle forests (ENF) on various sites in Germany, using freely available climate data and site information. A special focus was laid on the most recent years, i.e. the years since 2000, and on the year 2003 . Results are presented for the site Trier in the paper and for the other sites in the supplemental material. Model results were compared with Moderate Resolution Imaging Spectroradiometer (MODIS) GPP and NPP products.

\section{MATERIAL AND METHODS}

The latest available version of BiomeBGC (version 4.2) was used to model time series of NPP and other variables using climate data from different stations in Germany and typical ecophysiological and site constants for deciduous and coniferous forests.

Negative values of modeled NPP were taken as indicators for stressed vegetation.

\subsection{Preparation of climate data}

We used freely available climate data of 17 weather stations (Figure 1 and Table 1) from the German weather service DWD (DWD 2014). The data sets contain cloud cover, relative humidity, vapour pressure, air temperature, air pressure at

\footnotetext{
* Corresponding author.
} 
station height, wind speed, ground temperature minimum, air temperature minimum, air temperature maximum, maximum wind speed, precipitation, sun hours, and snow pack on a daily basis. The data are quality-checked by DWD and contain plausible values for all used years. BiomeBGC needs daily values of maximum, minimum, and mean air temperature, precipitation, water vapour pressure deficit, global radiation, and daylength. One of the easiest ways to transform the DWD data into BiomeBGC format is to use the model MTCLIM (Hungerford et al., 1989; Thornton and Running, 1999) that is designed for transferring data from a climate station to another location at a different height but can also be used to calculate the variables missing from the DWD data without adaption to a different height.

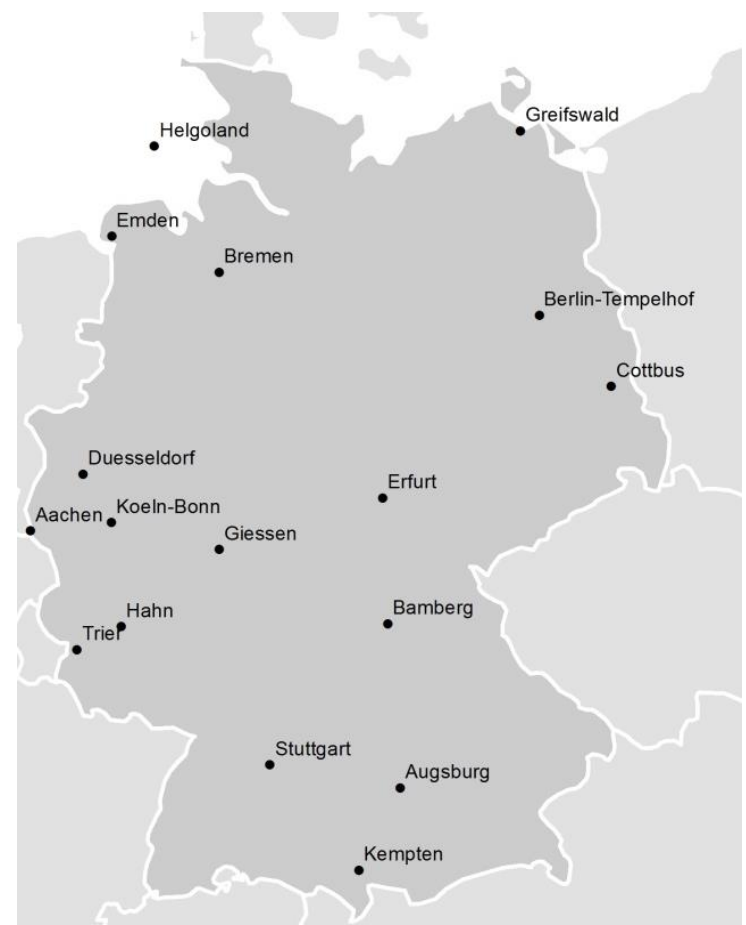

Figure 1. Weather stations used for BiomeBGC modelling

\begin{tabular}{|c|c|c|c|c|}
\hline & $\begin{array}{l}\text { Longitude } \\
{\left[{ }^{\circ} \mathrm{E}\right]}\end{array}$ & $\begin{array}{l}\text { Latitude } \\
{\left[{ }^{\circ} \mathrm{N}\right]}\end{array}$ & $\begin{array}{l}\text { Height } \\
\text { [m asl.] }\end{array}$ & $\begin{array}{l}\text { Climate } \\
\text { data since }\end{array}$ \\
\hline Aachen & 6.0242 & 50.7981 & 231 & 1930 \\
\hline Augsburg & 10.9419 & 48.4253 & 461 & 1947 \\
\hline Bamberg & 10.9206 & 49.8742 & 240 & 1949 \\
\hline \multicolumn{5}{|l|}{ Berlin- } \\
\hline Tempelhof & 13.4019 & 52.4672 & 48 & 1948 \\
\hline Bremen & 8.7985 & 53.0445 & 4 & 1890 \\
\hline Cottbus & 14.3186 & 51.7775 & 69 & 1951 \\
\hline Duesseldorf & 6.7686 & 51.2958 & 37 & 1970 \\
\hline Emden & 7.2287 & 53.3881 & 0 & 1998 \\
\hline Erfurt & 10.9606 & 50.9828 & 316 & 1951 \\
\hline Giessen & 8.645 & 50.6031 & 203 & 1947 \\
\hline Greifswald & 13.4056 & 54.0967 & 2 & 1978 \\
\hline Hahn & 7.2644 & 49.9461 & 497 & 1999 \\
\hline Helgoland & 7.8920 & 54.1750 & 4 & 1953 \\
\hline Kempten & 10.3347 & 47.7231 & 705 & 1952 \\
\hline \multicolumn{5}{|l|}{ Koeln- } \\
\hline Bonn & 7.1572 & 50.8644 & 92 & 1958 \\
\hline Stuttgart & 9.2235 & 48.6883 & 371 & 1953 \\
\hline Trier & 6.6581 & 49.7478 & 265 & 1948 \\
\hline
\end{tabular}

\subsection{Model parameterization}

BiomeBGC uses three input files: (1) the model initialization file that contains information on how to run the model and the site information, (2) the ecophysiological constants (EPC) file that describes the biomes to be modelled, and (3) the climate file. In addition, a $\mathrm{CO} 2$ file with average annual atmospheric $\mathrm{CO} 2$ concentrations can be input.

A comprehensive study on model parameterization and sensitivity has been published by White et al. (2000). We used the standard EPC files for DBF and ENF delivered with the latest model version (version 4.2, available online at http://www.ntsg.umt.edu). Site conditions, i.e. soil composition and depth, site shortwave albedo and deposition and fixation of nitrogen are also set to model standard. The model was run in spin-and-go mode, i.e. an initialisation run was directly followed by the model run using the station climate data. In the initialisation run, the model starts with very low carbon and nitrogen pool values und runs until equilibrium is reached. This corresponds to natural conditions of undisturbed forest. The spin-up usually takes a few hundred to thousand model years.

\subsection{MODIS GPP and NPP}

The Numerical Terradynamic Simulation Group (NTSG) at the University of Montana in Missoula provides continuous estimates of GPP and NPP based on MODIS data (Zhao et al., 2005; Zhao and Running, 2010). The algorithm of the MOD17 product is based on the radiation use efficiency logic of Monteith (1972). Productivity of annual crops under wellwatered and fertilized conditions is assumed to be linearly related to the amount of absorbed Photosynthetically Active Radiation (APAR). APAR is transformed to a productivity estimate via a conversion efficiency parameter, $\varepsilon$, which varies by vegetation type and climate conditions. The algorithm incorporates differences in maximum $\varepsilon$ among vegetation types and also lowers $\varepsilon$ under water-stressed (Scale Water_Stress $_{\text {S }}$ ) and/or cold temperature (Scale ${ }_{T e m p)}$ conditions. To calculate NPP, MOD17 also estimates daily leaf and fine root maintenance respiration $\left(R_{l r}\right)$, annual growth respiration $\left(R_{g}\right)$, and annual maintenance respiration of live cells in woody tissue $\left(R_{m}\right.$; NTSG, 2015; Heinsch et al, 2003).The main MOD17 data outputs include:

$$
\begin{aligned}
& \mathrm{GPP}=\varepsilon_{\max } \cdot \text { Scale }_{\mathrm{Temp}} \cdot \text { Scale }_{\text {Water_Stress }_{\text {S }}} \cdot \mathrm{APAR} \\
& \mathrm{PS}_{\mathrm{Net}}=\mathrm{GPP}-R_{l r} \\
& \mathrm{NPP}=\sum \mathrm{PSNet}-R_{g}-R_{m}, \\
& \text { where } \mathrm{GPP}=8 \text {-day GPP } \\
& \mathrm{PS}_{\mathrm{Net}}=8 \text {-day Net Photosynthesis } \\
& \mathrm{NPP}=\text { Annual NPP. }
\end{aligned}
$$

A complementary product to MOD17 is the land cover product MOD12 that contains land cover classes suitable for BiomeBGC like deciduous broadleaved forests (DBF) and evergreen needle forests (ENF). Both MOD17 and MOD12 are provided at a spatial resolution of $1 \mathrm{~km}$.

Mean annual NPP for DBF and ENF was extracted from the data products by subsetting data of the tiles h18v03 and h18v04 (central Europe) to the area of Germany and selecting only pixels of the respective classes according to the MOD12 product. 


\section{RESULTS}

\subsection{General BiomeBGC results}

Figure 2 shows a typical scatter plot of the relationship between daily maximum temperature and NPP for DBF for one modelled year. Three areas with different relationships can be seen: During winter, outside of the vegetation period, NPP is slightly negative, independent of temperature (small points). Without leaves, the trees pause photosynthesis and thus have no GPP, but some respiration occurs. During the vegetation period, there is a positive correlation between temperature and NPP most of the time (circles), since high temperatures are correlated with high irradiance and thus high photosynthesis. As long as there is no shortage of water, the correlation is positive. In cases of drought stress, the correlation is inverted. Higher temperatures increase the stress and NPP takes on higher negative values (diamond symbols).

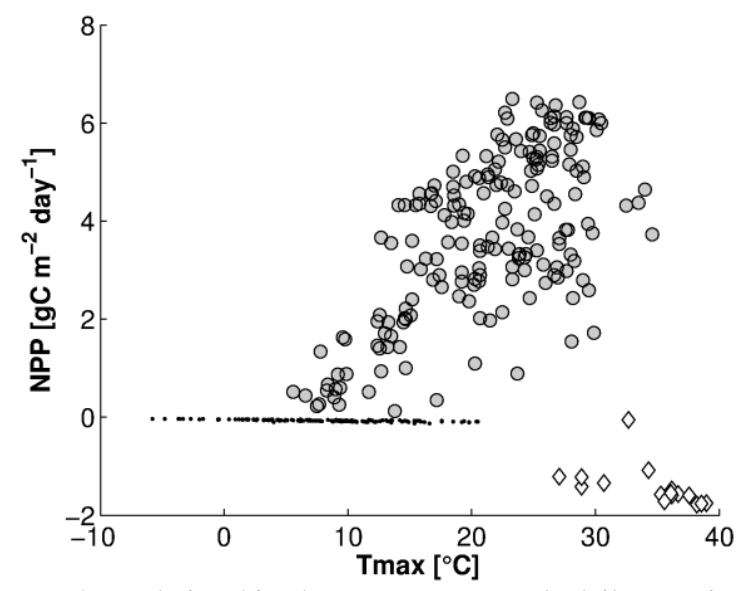

Figure 2. Relationship between NPP and daily maximum temperature (Tmax) for Trier 2003. Filled circles show the normal case of a positive correlation, hollow diamonds show the inverted correlation in stress situations, small points are outside the vegetation period.

Figure 3 figure shows VPD and leaf area index (LAI) for DBF in Trier in the year 2003, and some carbon pools according to BiomeBGC. The LAI exhibits only a slight decrease during the late summer stress phase. The carbon stored in vegetation has a similar shape to LAI, but with a clearer decline in late summer and a steady decline during winter, when no photosynthesis can be conducted but the trees must maintain respiration. Litter carbon goes down from November to September of the next year and is filled up when the leaves fall in autumn. Soil carbon has a very low variation during the year with an upward trend in the winter season when part of the litter is transformed into humus and a downward trend in the summer. The combination of all pools is shown in the bottommost plot of Figure 3; with a maximum in autumn when the year's photosynthesis is completed.
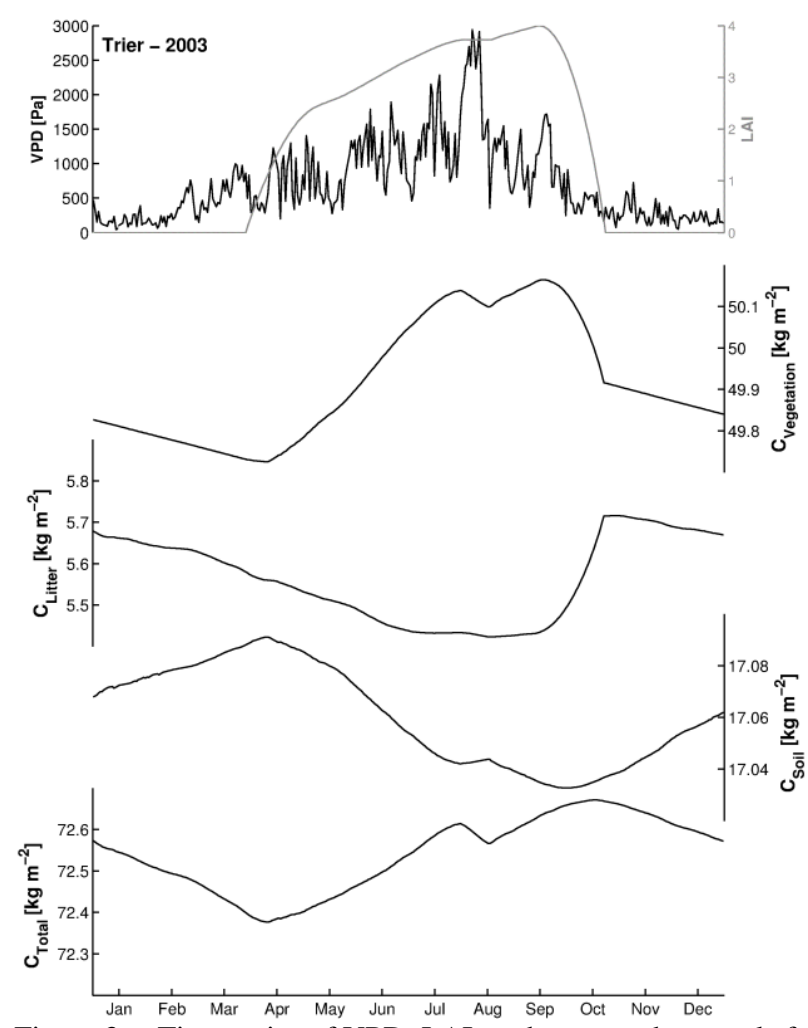

Figure 3. Time series of VPD, LAI, and some carbon pools for deciduous forest in Trier 2003

\subsection{BiomeBGC time series}

Figure 4 shows time series of NPP as simulated by BiomeBGC, and water vapour pressure deficit (VPD), as simulated by MTCLIM for the years 2000 to 2013 using the climate data of Trier and DBF ecophysiology. The typical seasonal variation with slightly negative NPP values in winter, rising values in spring and falling values in autumn is visible in every year. VPD values also are higher in the summer, but thy show high frequency changes and regularly fall near zero, i.e. water vapour saturated air. One can clearly see that in prolonged periods of high VPD, i.e. hot and dry summer periods, NPP becomes negative, i.e. the plants are stressed. The longest and deepest stress period occurs in the late summer of 2003 where a prolonged phase of high VPD causes severely negative NPP.

Figure 5 shows sums of negative NPP values during the vegetation period for DBF in Trier for all modelled years, i.e. 1948 to 2013 . While 2003 is the year with the highest negative NPP values since 2000, several years in the previous decades display even higher values. 


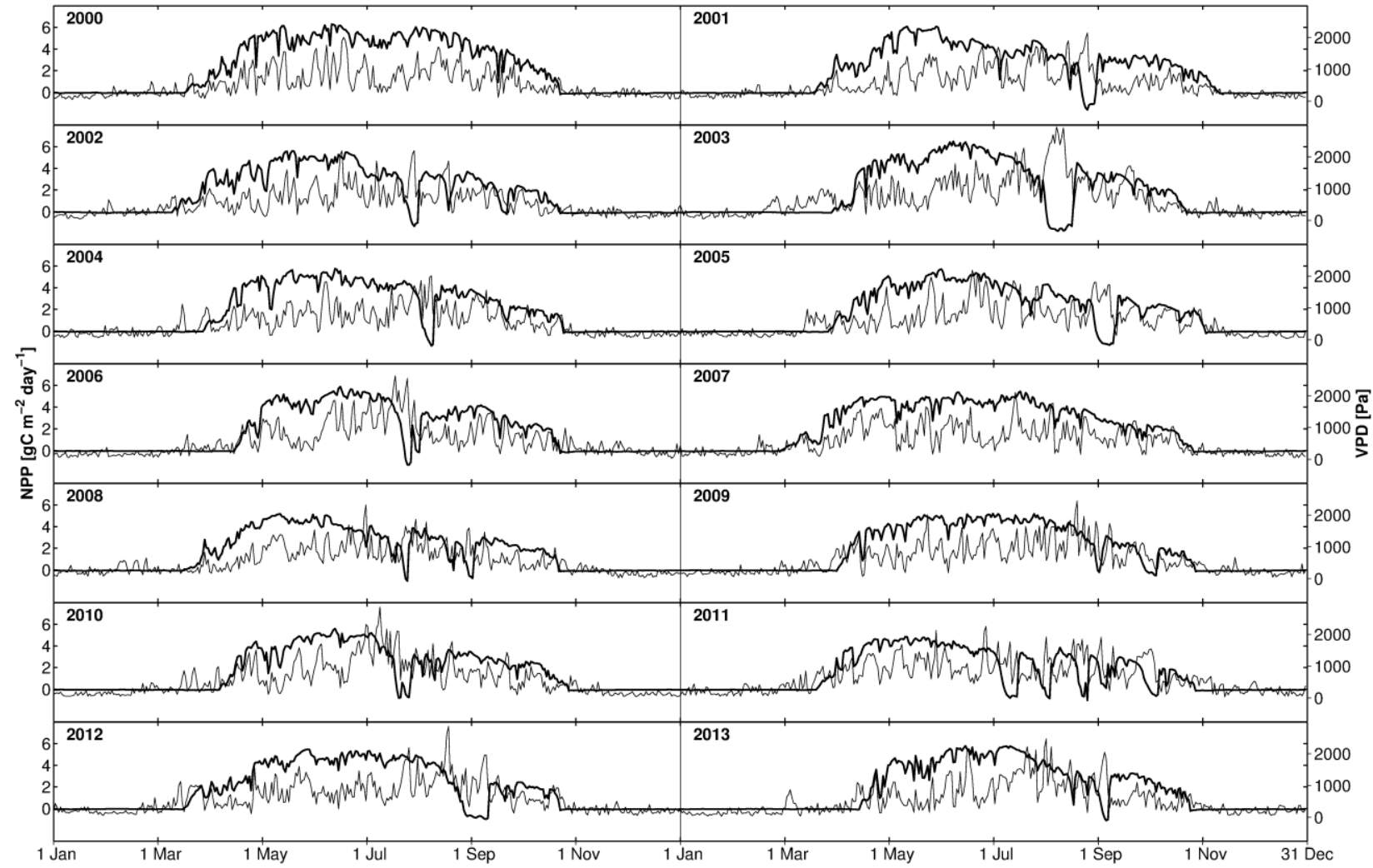

Figure 4. Time series of NPP (bold line) and VPD for deciduous forest in Trier. Phases of high VPD often correlate with negative NPP.

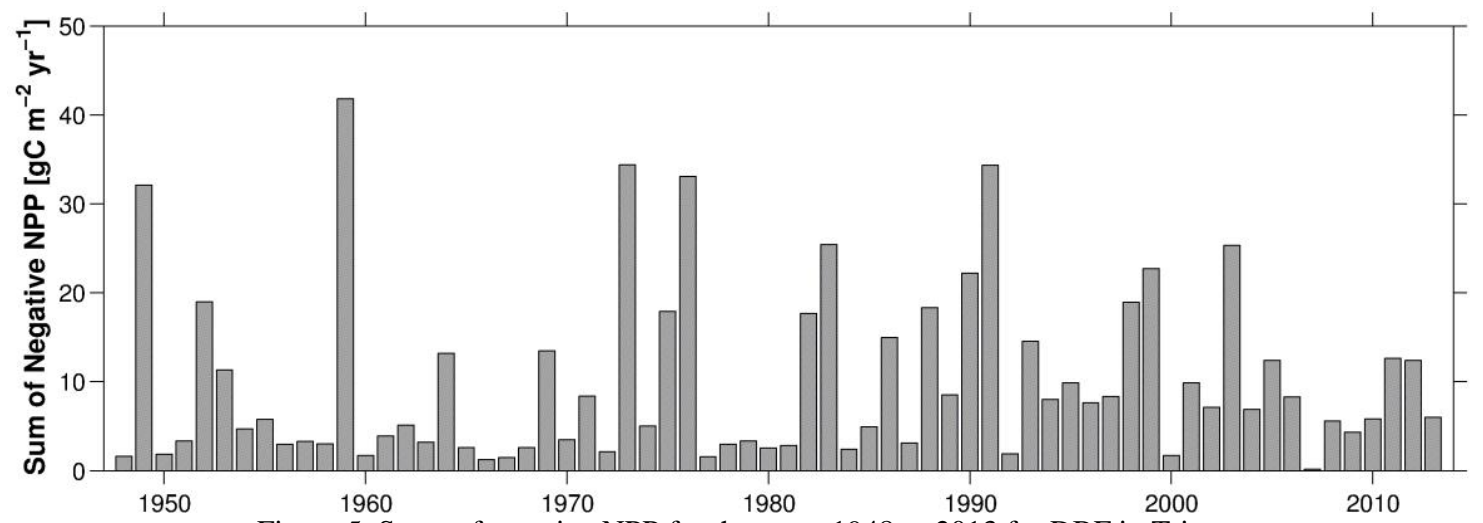

Figure 5. Sums of negative NPP for the years 1948 to 2013 for DBF in Trier.

\subsection{Comparison of different sites in Germany}

The modelled NPP time series of all considered sites showed plausible annual courses and clear variations between the years. As expected, sites in mountainous regions with lower average temperatures have shorter vegetation periods that start later than warmer sites. These cold sites rarely experience drought stress, e.g. at Kempten and Hahn 2003 was the only year with negative NPP values for DBF during the vegetation season. Apart from that, variations between the years were similar for most of the stations.

Figure 6 shows sums of negative NPP values during the vegetation periods of 2000 to 2013. Negative NPP values for each station have been normalized to the value range 0 to 1 , with 1 being the largest absolute sum of negative values. The plot shows the mean normalized values of the considered sites and the standard deviation between the sites. The year 2007 contained the least negative NPP values in every station; the year 2003 contained the most negative values in all but two stations. Exceptions are Helgoland where 2013 was the year with the most negative values, and Cottbus where 2006 was the year with the highest stress. 2001 and 2006 were the years with the highest variance between the sites.

Detailed model results, i.e. equivalents of figures 2 to 5 for all considered sites for both DBF and ENF, can be found in the additional material to this paper (see Appendix). 


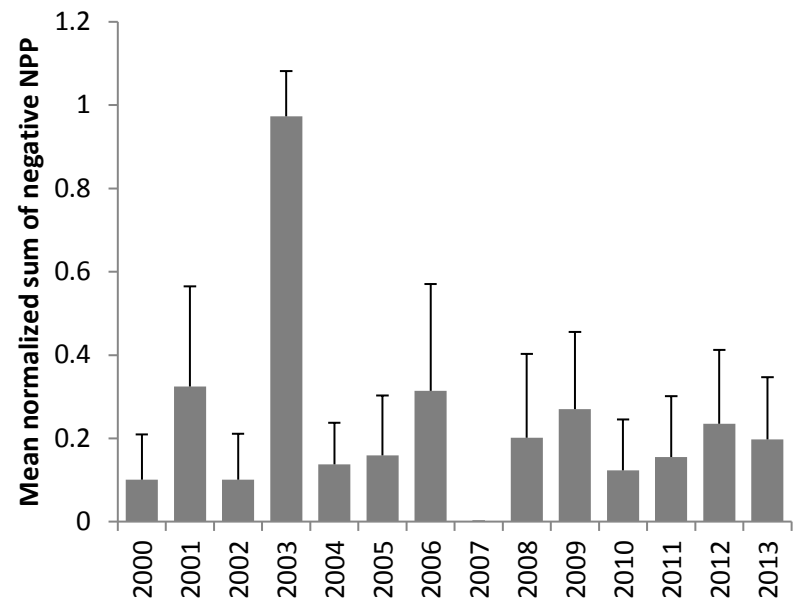

Figure 6. Sums of negative NPP for the years 2000 to 2013, normalized and aggregated for all considered weather stations. Error bars show standard deviation between stations. 2007 had no negative NPP values at any station.

\subsection{MODIS time series}

Figure 7 shows mean, standard deviation and minimum and maximum values of annual NPP of the years 2000 to 2010 for all MODIS DBF pixels in Germany. Variations between the years are rather small, but it can clearly be seen that 2003 had the lowest NPP and 2007 had the highest values. This is in agreement with the BiomeBGC model results presented in the previous figures, e.g. Figure 6 . Variation between most of the DBF pixels was limited as can be seen by the rather narrow corridor of standard deviations.

Figure 8 gives the 8-day GPP for the same pixels of the year 2003. The slump in late summer around day of year 220 is evident. Since the high temporal resolution is not available for NPP and the displayed GPP values do not include respiration (cf. equations 1-3), negative values are not reached.

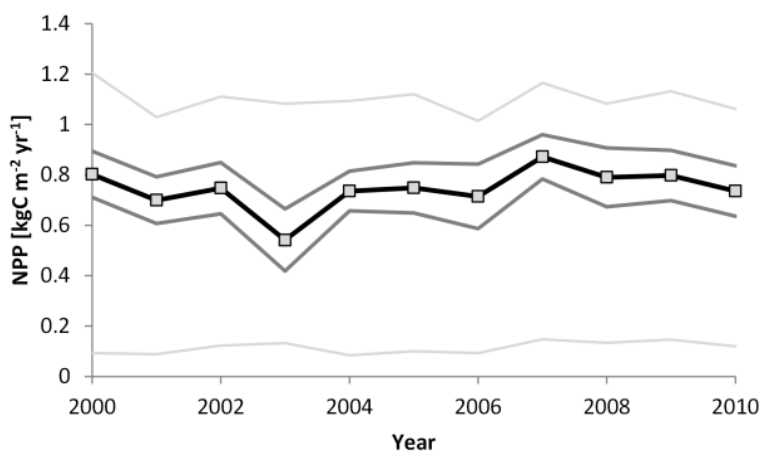

Figure 7. Time series of MODIS-derived NPP of deciduous broadleaf forest in Central Europe. The central line represents mean values, dark grey lines are mean $+/$ one standard deviation, light grey lines are minimum and maximum.

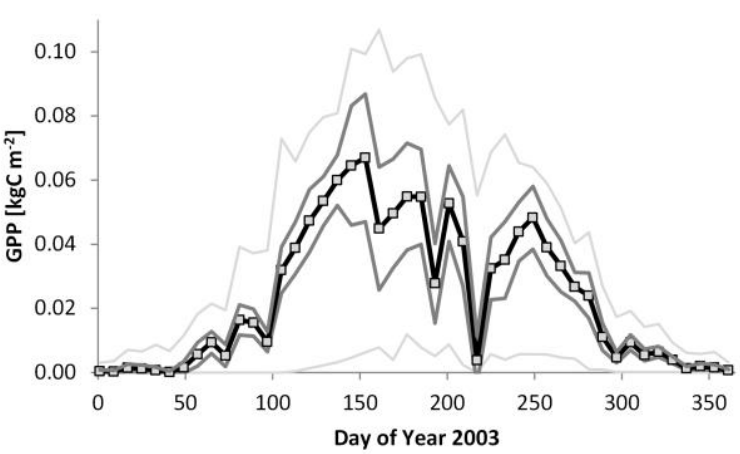

Figure 8. Time series of MODIS-derived GPP of deciduous broadleaf forest in Central Europe in 2003.

Figure 9 shows the spatial variation of the ratio of MOD17 NPP 2003 and 2007, i.e. the year with lowest primary productivity divided by the year with highest productivity, for Germany and surroundings. The spatial resolution of the map is $1 \mathrm{~km}$, so only large-scale variations are shown. Non-vegetated areas like water bodies and urban areas are masked and displayed in white. Dark areas indicate a strong contrast between the dry year 2003 and the moist year 2007, i.e. sites that are susceptible to dryness stress.

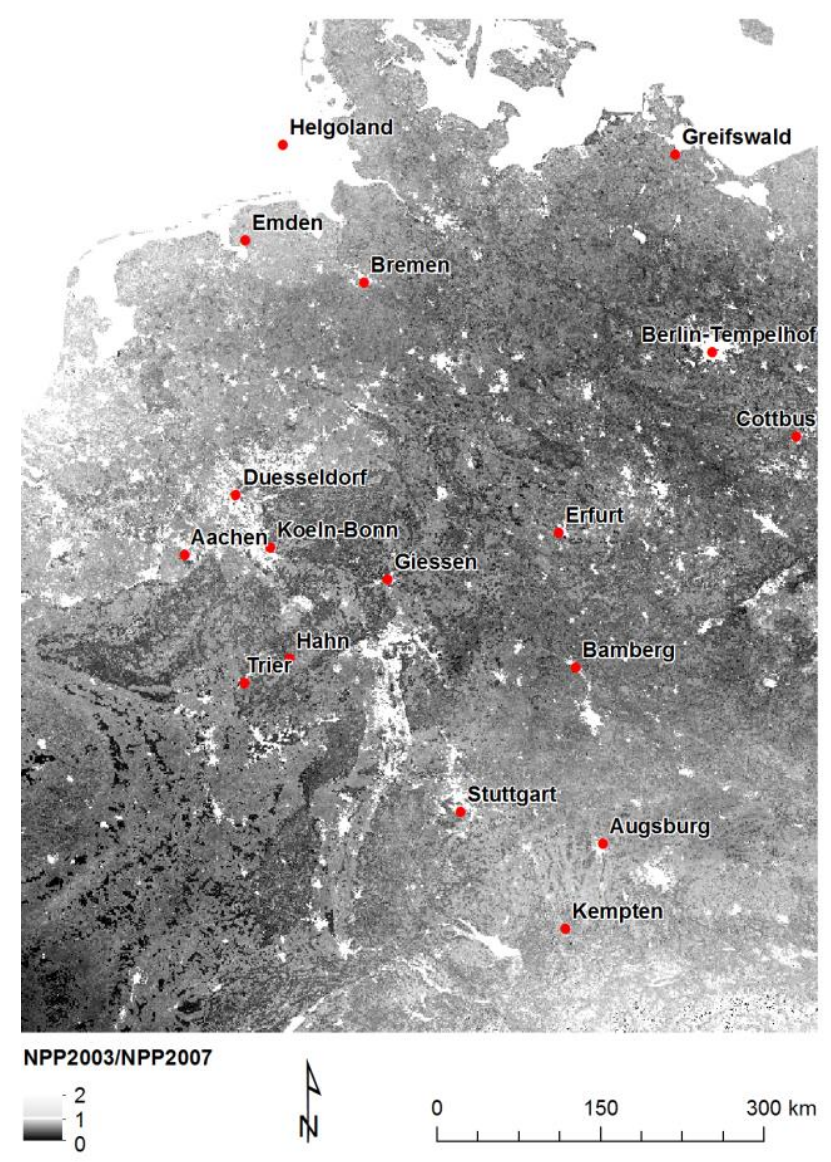

Figure 9. Ratio of MODIS NPP 2003 and 2007. 


\section{DISCUSSION}

\subsection{General BiomeBGC results}

Figures 2 and 3 show that plausible results can be obtained from BiomeBGC. The model reacts sensitively to weather changes and to variations in the EPC file, and the carbon pools are also plausible. The inversion of the relation between temperature and NPP in cases of low water availability illustrates the model's ability to detect stress situations for the trees.

\subsection{BiomeBGC time series}

Figures 4 and 6 underline the exceptional position of the year 2003. But for many climate stations other years like 1991, 1976, 1973, and 1959 (see Figure 5 for Trier and supplementary material for all sites) led to even more extreme stress. After 2003 , it was feared that years like that would become regular, but no comparable drought stress year has occurred since then in Germany. This should however not be interpreted as indication of an absence of climate change.

\subsection{Comparison of different sites in Germany}

While the general trends are similar at all sites, there are variations caused by the climatic site conditions. The diagrams shown here for Trier are available for all sites in the supplementary material. Of course, climate data is not enough for a thorough assessment whether a certain tree can planted at a certain site. For this, a more detailed site parameterization with respect to soil and other parameters as well as a more detailed parameterization of the EPC file for the tree species and variant is needed. In addition, a climate projection for the coming decades must be taken into account. All of this is beyond the scope of this paper where we wanted to assess the model sensitivity to different historic climate data sets.

\subsection{MODIS time series}

The satellite-derived NPP time series confirm the results achieved with BiomeBGC. While climate data is available only at certain points, the MODIS data is available for all vegetated areas. Both the multi-year NPP product and the intra-year GPP product agree well with the modelled results. An important difference is that the satellite data shows productivity of actual vegetation cover while the model can also deal with possible future vegetation and with alternative scenarios. The satellite data's spatial resolution of $1 \mathrm{~km}$ is another drawback. Pure deciduous or coniferous forests that cover entire pixels are rare in Germany, so most pixels have mixed land cover and are limited in their representativeness.

\section{CONCLUSIONS}

BiomeBGC can be used to assess forest stress resulting from climate and stand conditions. It can serve as a decision support tool if ecophysiological constants of various candidate tree species or varieties and site information are available. These can be used for simulations either with projected climate data for future decades, or with extreme years of the past to see how much they will suffer from drought stress.

The MODIS GPP and NPP products give the spatial distribution of biome productivity derived from satellitemeasured APAR and process modelling depending on a land cover classification for large areas. They show a good agreement with the BiomeBGC results that rely primarily on climate data, both data sets are able to indicate situations of drought stress in central European forests.

\section{ACKNOWLEDGEMENTS}

This research was supported within the framework of the EnMAP project (Contract No. 50 EE 1258) by the German Aerospace Center (DLR) and the German Federal Ministry of Economics and Technology.

\section{REFERENCES}

Bond-Lamberty, B., S. T. Gower, D. E. Ahl, and P. E. Thornton. 2005. Reimplementation of the Biome-BGC model to simulate successional change. Tree Physiology, 25 (4), pp. 41324.

Cienciala, E., and F. A. Tatarinov. 2006. Application of BIOME-BGC model to managed forests: 2. Comparison with long-term observations of stand production for major tree species. Forest Ecology and Management, 237 (1-3), pp. 25266.

DWD. Climate Date Germany - per Measuring Stations - Daily values.

http://www.dwd.de/bvbw/appmanager/bvbw/dwdwwwDesktop? _nfpb=true\&_pageLabel=_dwdwww_klima_umwelt_klimadate n_deutschland\&T82002gsbDocumentPath=Navigation $\% 2$ FOeff entlichkeit\%2FKlima__Umwelt\%2FKlimadaten $\% 2$ Fkldaten_k ostenfrei\%2Fausgabe_tageswerte_node.html $\% 3 \mathrm{~F} \_n n n \% 3 \mathrm{Dt}$ rue (2014-07-28)

Gobron, N., B. Pinty, F. Mélin, M. Taberner, M. M. Verstraete, A. Belward, T. Lavergne, and J. L. Widlowski. 2005. The state of vegetation in Europe following the 2003 drought. International Journal of Remote Sensing, 26 (9), pp. 2013-20.

Heinsch, F. A., M. Reeves, P. Votava, S. Kang, C. Milesi, M. Zhao, J. Glassy, W. M. Jolly, R. Loehman, C. F. Bowker, J. S. Kimball, R. R. Nemami, and S. W. Running. 2003. User's GuideGPP and NPP (MOD17A2/A3) Products NASA MODIS Land Algorithm. http://www.ntsg.umt.edu/sites/ntsg.umt.edu/ files/modis/MOD17UsersGuide.pdf (04 March 2015).

Hungerford, R. D., R. R. Nemani, S. W. Running, and J. C. Coughlan. 1989. MTCLIM: A Mountain Microclimate Simulation Model. In, 56. United States Department of Agriculture, Forest Service.

Hunt, E. R., F. C. Martin, and S. W. Running. 1991. Simulating the effects of climatic variation on stem carbon accumulation of a ponderosa pine stand: comparison with annual growth increment data. Tree Physiology, 9, pp.161-71.

Kimball, J. S., P. E. Thornton, M. A. White, and S. W. Running. 1997. Simulating forest productivity and surfaceatmosphere carbon exchange in the BOREAS study region. Tree Physiology, 17 (8-9), pp. 589-99.

Monteith, J. L. 1972. Solar Radiation and Productivity in Tropical Ecosystems. The Journal of Applied Ecology, 9 (3), pp. 747-66.

NTSG. 2015. MODIS GPP/NPP Project (MOD17). http://www.ntsg.umt.edu/project/mod17 (04 March 2015). 
Pietsch, S. A., and H. Hasenauer. 2006. Evaluating the selfinitialization procedure for large-scale ecosystem models. Global Change Biology, 12 (9), pp. 1658-69.

Pietsch, S. A., H. Hasenauer, J. Kučera, and J. Čermák. 2003. Modeling effects of hydrological changes on the carbon and nitrogen balance of oak in floodplains. Tree Physiology, 23 (11), pp. 735-46.

Running, S. W., and J. C. Coughlan. 1988. A general model of forest ecosystem processes for regional applications I. Hydrologic balance, canopy gas exchange and primary production processes. Ecological Modelling, 42 (2), pp. 125-54.

Running, S. W., and S. T. Gower. 1991. FOREST-BGC, A general model of forest ecosystem processes for regional applications. II. Dynamic carbon allocation and nitrogen budgets. Tree Physiology, 9 (1-2), pp. 147-60.

Schlerf, M., H. Buddenbaum, M. Vohland, W. Werner, P. H. Dong, and J. Hill. 2005. Assessment of Forest Productivity using an Ecosystem Process Model, Remotely Sensed LAI Maps and Field Data. In Proceedings 1st Goettingen GIS and Remote Sensing Days, Goettingen, Germany.

Tatarinov, F. A., and E. Cienciala. 2006. Application of BIOME-BGC model to managed forests: 1 . Sensitivity analysis. Forest Ecology and Management, 237 (1-3), pp. 267-79.

Thornton, P. E., B. E. Law, H. L. Gholz, K. L. Clark, E. Falge, D. S. Ellsworth, A. H. Goldstein, et al. 2002. Modeling and measuring the effects of disturbance history and climate on carbon and water budgets in evergreen needleleaf forests. Agricultural and Forest Meteorology, 113 (1-4), pp. 185-222.
Thornton, P. E., and S. W. Running. 1999. An improved algorithm for estimating incident daily solar radiation from measurements of temperature, humidity, and precipitation. Agricultural and Forest Meteorology, 93 (4), pp. 211-28.

White, M. A., P. E. Thornton, S. W. Running, and R. R. Nemani. 2000. Parameterization and Sensitivity Analysis of the BIOME-BGC Terrestrial Ecosystem Model: Net Primary Production Controls. Earth Interactions, 4 (3), pp. 1-85.

Zhao, M., and S. W. Running. 2010. Drought-induced reduction in global terrestrial net primary production from 2000 through 2009. Science, 329, pp. 940-3.

Zhao, M., F. A. Heinsch, R. R. Nemani, and S. W. Running. 2005. Improvements of the MODIS terrestrial gross and net primary production global data set. Remote Sensing of Environment. 95, pp. 164-76.

\section{APPENDIX}

Additional supporting material to this paper can be downloaded at http://www.uni-trier.de/fileadmin/fb6/prof/FER/isupp.pdf

The supplementary material contains BiomeBGC modelling results for all considered sites. 